\title{
ESTIMATES FOR THE MODULII OF THE ZEROS OF A POLYNOMIAL
}

\author{
AbDUl AZIZ AND AliYa QAYOOM
}

\begin{abstract}
In this paper, we prove a more general result concerning the location of the zeros of a polynomial in a ring shaped region from which we deduce an interesting and significant refinement of a classical result of Cauchy. A variety of other results, which in particular include several known extensions and generalizations of Enestrom - Kakeya Theorem, can be established from this result by a fairly uniform procedure.
\end{abstract}

Mathematics subject classification (2000): 30C15, 26C10.

Key words and phrases: polynomials, zeros, Fibonacci's numbers, Enstrome-Kakeya theorem.

\section{REFERENCES}

[1] A. AzIZ, Q. G. MoHAMmad, Zero-free Regions for Polynomials and some Generalizations of EnestromeKakeya Theorem, Canad. Math.Bull., 27, 3, (1984), 265-272.

[2] P. Borwein, T. Erdelyi, Polynomial and Polynomial Inequalities, Springer-Verlag, Beijing, 1997, pp. $16-17$.

[3] J. L. Diaz Barrero, An Annulus for the Zero's of Polynomials, J. Math. Anal. Appl.. 273, (2002), 349-352.

[4] A. Joyal, G. Labelle And Q. I. Rahman, On the Location of the Zero's of Polynomials, Canadian Math, Bull., 10, (1967), 53-63.

[5] M. Marden, Geometry of Polynomials, IInd Ed., Math, Surveys, No.3, Amer.Math.Soc. Providence, R.I, 1966.

[6] G. V. Milovanović, D. S. Mitrinović and Th. M. Rassias, Topics in Polynomials; Extremal Problems, Inequalities Zeros, World Scientific, Singapore, New Jersey, London, Hong-Kong, 1994.

[7] G. V. Milovanović, T. M Rassias, Inequalities for Polynomial Zeros in T.M.Rassias [Ed], Survey on Classical Inequalities, Kluwer Academic, Netherlands, 2000, pp. 165-202.

[8] G. V. Milovanović, T. M RASSiAs, Distribution of Zeros and Inequalities for zeros of algebraic polynomials in T. M Rassias, [Ed], Functional Equations and Inequalities, Kluwer Academic, Dordrecht, 2000, pp. 171-204.

[9] Q. I. Rahamn, G. SchmeIsser, Analytic Theory of Polynomials, Clarendon Press-Oxford 2002, pp. 243-270.

[10] I. NiVERI, H. S. ZuCKERMAN, An Introduction to the Theory of Numbers, Third Ed., Wiley Easter Limited, 1972.

[11] J. L. WALSH, An Inequality for the Roots of an Algebraic Equation, Ann. of Math. 25, (1924), 749-754. 